\title{
WHO hopes Ebola incidence will decline after peaking in December
}

\author{
Anne Gulland \\ London \\ The World Health Organization is aiming to ensure that the \\ number of new cases of Ebola disease does not rise to more \\ than 10000 cases a week by the beginning of December and \\ then starts to fall.
}

The goal is part of a new programme introduced by the United Nations Mission for Emergency Response, which aims that within 60 days from mid-October $70 \%$ of new infections will be isolated and $70 \%$ of burials will be safe. And within 90 days the goal is that the number of new infections will be decreasing in $80 \%$ of areas affected by Ebola disease.

WHO's director general, Bruce Aylward, told a telephone press conference that as at 14 October there had been 8914 cases of Ebola disease, including 4447 deaths, but that the numbers would continue to rise over the next few months.

He admitted that achieving the goal would be difficult but that in Monrovia, Liberia's capital, health officials were close to achieving it. However, he added, "There are going to be big challenges in achieving this, but measuring it will also be very difficult."

Aylward said that two recent trends were causing concern: the greater geographical spread of the disease and the increasing incidence in the capitals of Sierra Leone and Guinea.

For the past three to four weeks the number of cases has been increasing steadily by about 1000 each week but this did not mean that disease progression was starting to slow down, said Aylward. Numbers fluctuated, he said, and laboratories could not always keep up with the number of specimens they received. "Any sense that the great effort kicked off over the last couple of months is already starting to see an impact - that would be premature," he said.

Aylward added that the international response had improved, and he lauded in particular the UK and the US, but he said there was "a lot of resources but not a lot of cash." He also said that many of the people sent in to help had no experience in treating Ebola disease. "The challenge is making sure all of that [activity] adds up to the kind of plan we need that will stop this disease," he said.

Recruiting international staff was also a challenge, he said, but treatment centres set up by the UK and US would go some way to allaying the understandable fears of international staff, as they were dedicated to the treatment of international responders and had improved medical evacuation facilities.

Meanwhile, in the UK this week staff from Public Health England have begun screening at Heathrow and Gatwick airports and the Eurostar terminals, requiring travellers from Sierra Leone, Liberia, and Guinea to fill in questionnaires asking about their current health, recent travel history, and whether they might be at potential risk through contact with patients with Ebola disease. ${ }^{1}$ In some cases they are taking travellers' temperature, and some passengers also have to give contact details to staff.

Passengers who report recent exposure to Ebola disease or who display symptoms will undergo a clinical assessment and, if necessary, will be transferred to hospital. Those displaying no symptoms will be told how to contact the NHS if they later feel unwell. Passengers identified as having no symptoms but who are at an increased risk of having come into contact with Ebola will be given a Public Health England contact number, and the agency will contact those at high risk every day until the 21 day incubation period is over.

"Should they develop symptoms they will have the reassurance of knowing this system will get them first class medical care, as the NHS demonstrated with Nurse William Pooley, and the best possible chance of survival," Jeremy Hunt, England's health secretary, told the House of Commons on Monday 13 October. Hunt said that screening would probably miss about one in 10 travellers, as there were no direct flights from the three affected countries to the UK and some travellers would not enter the country through the screening hubs. Information will be displayed at all entry points to the UK asking passengers who have been to the affected countries in the past 21 days to identify themselves to staff.

The Spanish nurse who contracted the Ebola virus after caring for two Spanish missionaries repatriated after becoming infected in west Africa is still in isolation, but the Spanish health ministry has said that the amount of virus in her blood was diminishing. Fifteen other patients, including the nurse's husband, are in isolation but are not showing any symptoms of Ebola disease. A UN official, thought to be Sudanese, has also died in a hospital in Germany. The man was flown to Leipzig for treatment on 13 October but died the next day.

Meanwhile in the US a nurse has tested positive for Ebola disease after caring for a patient who died from the disease at Texas Presbyterian Hospital. ${ }^{2}$ The patient is in isolation, and the US Centers for Disease Control said it was confident that further spread in the community could be avoided by contact tracing, health monitoring, and isolation of people who developed symptoms. ${ }^{3}$ 
Gulland A. Experts question usefulness of screening travellers to UK for Ebola. BMJ 2014;349:g6199.

McCarthy M. Texas healthcare worker is diagnosed with Ebola. BMJ 2014;349:g6200. McCarthy M. US to "rethink" Ebola infection control after nurse falls ill. $B M J$ 2014;349:g6240.
Cite this as: BMJ 2014;349:g6255

(c) BMJ Publishing Group Ltd 2014 